\title{
Tissue specificity of methylation and expression of human genes coding for neuropeptides and their receptors, and of a human endogenous retrovirus $\mathrm{K}$ family
}

Received: 9 January 2006/ Accepted: 23 January 2006/Published online: 17 March 2006

(C) The Japan Society of Human Genetics and Springer-Verlag 2006

\begin{abstract}
The purpose of the present study was to understand the tissue specificity of DNA methylation and the relationship between methylation and expression of genes with essential roles in neurodevelopment and brain function. We chose dopamine receptor genes (DRD1 and DRD2), NCAM, and COMT as examples of genes with $\mathrm{CpG}$ islands around the promoter region, and serotonin receptor genes (HTR2A and HTR $3 A$ ), $H C R T$, and $D R D 3$ as genes without $\mathrm{CpG}$ islands. Methylation states were investigated in fetal brain, fetal liver, placenta, and in adult peripheral leukocytes from three individuals by Southern blot and bisulfite-modified DNA sequencing. A repetitive sequence, human endogenous retrovirus (HERV)-K was also examined. All genes examined were almost completely unmethylated in brains. The genes with $\mathrm{CpG}$ islands were unmethylated regardless of their expression state. In contrast, genes without $\mathrm{CpG}$ islands showed various methylation patterns, which did not necessarily reflect the transcriptional activity of the genes. Most HERV-K loci were methylated, but some loci showed relatively low methylation in the placenta and liver. Interestingly, we found inter-individual differences in methylation levels in HTR2A and HCRT in the placenta and in some loci of HERV-K in the placenta and liver. The sample with the lowest methylation levels in the two unique
\end{abstract}

H. Shen · A. Nakamura $\cdot$ J. Sugimoto $\cdot$ T. Oda $\cdot$ Y. Jinno $(\bowtie)$ Department of Molecular Biology,

Ryukyu University School of Medicine, 207 Nishihara, Okinawa 903-0215, Japan

E-mail: sirius@med.u-ryukyu.ac.jp

Tel.: + 81-98-8953331

Fax: $+81-98-8951438$

A. Nakamura $\cdot$ N. Sakumoto Department of Neuropsychiatry,

Ryukyu University School of Medicine, Okinawa, Japan

Y. Okazaki

Department of Neuropsychiatry,

Mie University School of Medicine, Mie, Japan genes showed higher methylation of HERV-K loci than the other samples. These results provide detailed information about the methylation states of the genes analyzed and evidence for inter-individual variations in methylation in both unique and repetitive sequences.

Keywords Tissue specificity - DNA methylation · Gene expression - Dopamine and serotonin receptors · Human endogenous retrovirus

\section{Introduction}

Epigenetic modifications are involved in a wide range of normal and pathological cellular phenomena (Jones and Laird 1999; Jaenisch and Bird 2003). Cytosine methylation in $\mathrm{CpG}$ and some $\mathrm{CpNpG}$ sequences is the sole epigenetic modification of DNA with known biological functions. One of these functions is gene regulation through the construction of heterochromatin (Razin 1998). Unusual hypermethylation has often been observed in tumors in the promoter regions of tumor suppressor genes (Jones and Laird 1999).

Aberrant epigenetic modifications occur not only in somatic cells, resulting in tumors, but also in some inherited diseases (Bickmore and van der Maarel 2003). Mental dysfunction is a major symptom in most inherited diseases with aberrations in epigenetic modifications. The neurodevelopmental disorder Rett syndrome is caused by mutations in a methyl-CpG-binding protein, $\mathrm{MeCP} 2$, and the characteristic clinical features partially resemble those observed in autism and schizophrenia (Robertson and Wolffe 2000; Shahbazian and Zoghbi 2002). Rett syndrome is a typical example of the implications of epigenetic modifications such as DNA methylation, and suggests that accurate fine-tuning of gene expression by epigenetic mechanisms is essential for normal brain function.

Studies on the role of DNA methylation in the pathogenesis of psychiatric disorders have increased in recent 
years but are still few in number, which may be due to the unique features of DNA methylation as well as the technical challenges involved in correlating methylation with particular pathologies. DNA methylation undergoes a genome-wide erasure and re-establishment during embryogenesis and shows tissue-specific patterns, as does gene expression (Hsieh 2000). It is evident that two major psychiatric disorders, schizophrenia and bipolar disorder, are inherited illnesses, and it is also true that both disorders are greatly influenced by environmental conditions (Abdolmaleky et al. 2005). Although seemingly paradoxical, DNA methylation could explain both the ambiguous inheritance and the roles of environmental factors in the etiology of these disorders. There is increasing evidence that some epigenetic signals may exhibit partial meiotic stability and can be transmitted from one generation to the next (Roemer et al. 1997; Morgan et al. 1999; Sutherland et al. 2000; Rakyan et al. 2002). Similarly, mitotic transmission of DNA methylation patterns demonstrates partial stability, but such patterns can be changed by hormones, nutritional factors, aging, or stochastic events in the cell (Wolff et al. 1998; Ahuja and Issa 2000; Thomassin et al. 2001).

In the present study, we examined the DNA methylation status of eight genes that are actively expressed in the brain: the dopamine receptors $D R D 1, D R D 2$, and $D R D 3$, catechol-O-methyltransferase (COMT), neural cell adhesion molecule $(N C A M)$, the 5-hydroxytryptamine receptors $H T R 2 A$ and $H T R 3 A$, and hypocretin (HCRT; also called orexin). DRD1,DRD2, COMT, and $N C A M$ harbor $\mathrm{CpG}$ islands around the promoter regions and the other four genes do not. In addition to these eight single copy genes, we also examined methylation states in the $5^{\prime}$ long terminal repeat (LTR) of the human endogenous retrovirus (HERV)-K family in order to compare patterns between unique sequences and repetitive sequences, as well as to examine possible interindividual differences.

\section{Materials and methods}

\section{DNA and RNA}

In the present study, we used DNA and RNA extracted from human fetal whole brains, fetal livers, placentas, and from peripheral blood leukocytes (PBL) of healthy volunteers. We prepared DNA using the standard proteinase K/phenol method (Sambrook et al. 1989). RNA from tissues other than PBL was extracted by the guanidine/CsCl method (Sambrook et al. 1989). RNA from PBL was isolated using ISOGEN (Nippon Gene, Japan) according to the manufacturer's instructions. DNA and RNA from fetal tissues and placentas were all from samples obtained in 1997. The fetuses (and placentas) were artificially aborted at 16 (Sample a), 19 (Sample b), and 21 (Sample c) weeks of gestation. Detailed information on the fetuses was not available.
Methylation analyses

We examined the methylation states of the eight single copy genes by Southern blot hybridization and using the sodium bisulfite-modified DNA sequencing method. HERV-K methylation was examined by Southern blot hybridization alone. Using the Grail 1.3 program (http://www.compbio.ornl.gov/Grail-1.3/), we confirmed that the sequences to be analyzed satisfied the established definition of a $\mathrm{CpG}$ island. DNA was first digested with appropriate non-methylsensitive restriction enzymes to yield a distinct band(s) in the methylation analysis by Southern blot hybridization. The restriction digests were then digested with methylsensitive restriction enzymes (10 U/ $\mu \mathrm{g}$ DNA), separated on $0.8 \%$ agarose gels, and transferred to Hybond- $\mathrm{N}^{+}$ membrane (Amersham Biosciences, Piscataway, NJ). Probes for the Southern blot hybridization were amplified by PCR, cloned into the pGEM-T easy vector (Promega, Madison, WI), and confirmed by sequencing. Probe DNA was labeled with $\left[\alpha-{ }^{32} \mathrm{P}\right] \mathrm{dCTP}$ using a Megaprime DNA Labeling kit (Amersham Biosciences). Primer sequences and temperatures for the final wash of the hybridized membranes are shown in Table 1 . The blots were hybridized in $6 \times \mathrm{SSC} / 0.5 \% \mathrm{SDS}$ at $65^{\circ} \mathrm{C}$ overnight and were sequentially washed in $2 \times \mathrm{SSC} / 0.1 \%$ SDS at $55^{\circ} \mathrm{C}$ and in $0.1 \times \mathrm{SSC} / 0.1 \%$ SDS at the appropriate temperatures (Table 1).

Sodium bisulfite treatment was carried out as described (Grunau et al. 2001), with minor modifications. The bisulfite-treated DNA was amplified by PCR using the following conditions: denaturation at $94^{\circ} \mathrm{C}$ for $3 \mathrm{~min}$, followed by 35 cycles of $94^{\circ} \mathrm{C}$ for $1 \mathrm{~min}$, annealing temperature (see Table 2) for $1 \mathrm{~min}, 72^{\circ} \mathrm{C}$ for $1 \mathrm{~min}$, and a final elongation at $72^{\circ} \mathrm{C}$ for 5 min with a GeneAmp PCR System 9600 (Applied Biosystems, Foster City, CA). Nested PCR was performed for 25 cycles. The primer sequences and sizes and positions of the regions analyzed are shown in Table 2. The primer sequences were designed using a program for predicting modified sequences (Singal and Grimes 2001). The PCR products were cloned into the pGEM-T easy vector (Promega), and ten clones each were sequenced using a BigDye sequencing kit (Applied Biosystems). In the case of the $\mathrm{CpG}$ island genes, we performed the methylation analysis using the bisulfite method only for fetal brain and adult PBL from one fetus and one person, respectively.

\section{Reverse transcription-PCR}

RNA used for RT-PCR was pre-treated twice with 10 to 30 U RNase-free DNase I (Roche, Mannheim, Germany) for $40 \mathrm{~min}$ at $37^{\circ} \mathrm{C}$. DNase I-treated total RNA $(5 \mu \mathrm{g})$ was reverse-transcribed with random primers and the M-MLV reverse transcriptase (Invitrogen, La Jolla, $\mathrm{CA}$ ) for $1 \mathrm{~h}$ at $37^{\circ} \mathrm{C}$ in a $20 \mu \mathrm{l}$ reaction mix. The reverse transcription products were diluted 6- to 25 -fold and $2 \mu \mathrm{l}$ used for PCR (18-36 cycles) in a total volume of 
Table 1 Southern blot analysis: primers for probe generation and wash conditions. COMT Catechol-O-methyltransferase, DRD1 dopamine receptor D1, DRD2 dopamine receptor D2, NCAM neural cell adhesion molecule, HTR2A 5-hydroxytryptamine receptor 2A, HCRT hypocretin, DRD3 dopamine receptor D3, $H T R 3 A$ 5-hydroxytryptamine receptor 3A, HERV-K human endogenous retrovirus $\mathrm{K}$

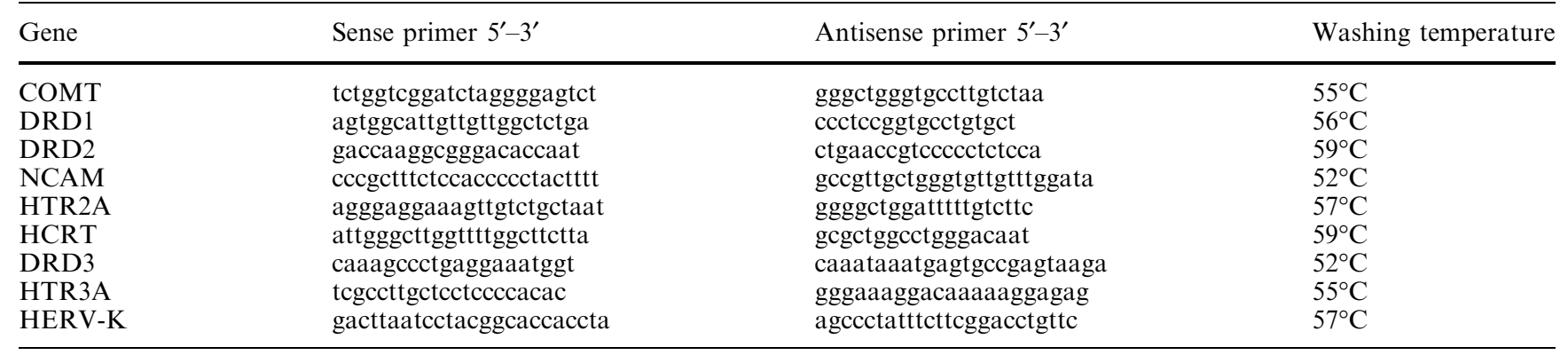

Table 2 A brief summary of PCR conditions and locations analyzed by the bisulfite method. $S$ Sense-strand, $A$ antisense-strand. Gene symbols as in Table 1

\begin{tabular}{|c|c|c|c|c|c|}
\hline Gene & PCR & Primer $5^{\prime}-3^{\prime}$ & Length (location) ${ }^{\mathrm{a}}$ & Accession no. ${ }^{\mathrm{b}}$ & Annealing temperature \\
\hline \multirow[t]{4}{*}{ COMT } & First & S: tttagtttttttatttgggaaggg & \multirow{4}{*}{$\begin{array}{l}290 \text { bp } \\
-239 \text { to }+51 \\
43384-43673\end{array}$} & & \multirow[t]{4}{*}{$52^{\circ} \mathrm{C}$} \\
\hline & & A: acaaccetaactaccccaaaaac & & NM_000754 & \\
\hline & Second & S: tttttgagtaagattagattaagaggt & & AC000090.3 & \\
\hline & & A: acaacctaactaccccaaaaac & & & \\
\hline \multirow[t]{4}{*}{ DRD1 } & First & S: gttaggggttgattttaagagg & & \multirow[t]{4}{*}{$54^{\circ} \mathrm{C}$} \\
\hline & & A: aaacactcccaaaactaatcaccta & -305 to +91 & NM_000794 & \\
\hline & Second & S: tgagttttgtttttaggggatttaa & & AC091393.3 & \\
\hline & & A: accttcaaccetacaaaacaaaac & & & \\
\hline \multirow[t]{4}{*}{ DRD2 } & First & S: gtygtagagttgtttagttttagtgt & \multirow{4}{*}{$\begin{array}{l}239 \text { bp } \\
-45 \text { to }+194 \\
111269-111507\end{array}$} & & \multirow[t]{4}{*}{$58^{\circ} \mathrm{C}$} \\
\hline & & A: crcacaaacttctaatcctaacct & & NM_000795 & \\
\hline & Second & S: gggtygggagttagggat & & AP002840.3 & \\
\hline & & A: crcacaaacttctaatcctaacct & & & \\
\hline \multirow[t]{4}{*}{ NCAM } & First & S: ggaaggttgggtagtaggag & \multirow{4}{*}{$\begin{array}{l}335 \text { bp } \\
-284 \text { to }+51 \\
95902-96236\end{array}$} & & \multirow[t]{4}{*}{$55^{\circ} \mathrm{C}$} \\
\hline & & A: cctaaaaacaaacaattaccaaac & & NM_181351 & \\
\hline & Second & S: gaaattttagtttttttagggag & & AP0000802.5 & \\
\hline & & A: atttttacaaaattatttcctacc & & & \\
\hline \multirow[t]{4}{*}{ HTR2A (upstream) } & First & S: tatyatattatgytggtggaagat & \multirow{4}{*}{$\begin{array}{l}220 \text { bp } \\
-741 \text { to }-521 \\
45919-46138\end{array}$} & & \multirow[t]{2}{*}{$46^{\circ} \mathrm{C}$} \\
\hline & & A: aaatacatccartrttaatcccata & & NM_000621 & \\
\hline & Second & S: tggtggaagatyaagaagagggga & & AL160397.17 & $57^{\circ} \mathrm{C}$ \\
\hline & & A: acaactttcctccetrraaattctcatt & & & \\
\hline \multirow[t]{4}{*}{ HTR2A (downstream) } & First & S: ttgattgtatgttattttaataatattgttgttaa & \multirow{4}{*}{$\begin{array}{l}356 \text { bp } \\
-304 \text { to }+52 \\
45346-45701\end{array}$} & & \multirow[t]{2}{*}{$52^{\circ} \mathrm{C}$} \\
\hline & & A: ttaatatacccacactctataacactaaaactaata & & NM_000621 & \\
\hline & Second & S: tgttattttaataatattgttgttaaattagtatt & & AL160397.17 & $51^{\circ} \mathrm{C}$ \\
\hline & & A: cacactctataacactaaaactaatatacatactat & & & \multirow{3}{*}{$50^{\circ} \mathrm{C}$} \\
\hline \multirow[t]{4}{*}{ HCRT } & First & S: ttttttatgaaggaagaagg & \multirow{4}{*}{$\begin{array}{l}410 \text { bp } \\
-399 \text { to }+11 \\
57183-57592\end{array}$} & & \\
\hline & & A: ccaaaaaccttaaaactatc & & NM_001524 & \\
\hline & Second & S: gattgttgttggttgtttta & & AC099811.7 & $57^{\circ} \mathrm{C}$ \\
\hline & & A: tatcaattataacccactcc & & & \\
\hline \multirow[t]{3}{*}{ DRD3 } & First & S: ggtaattaaattgaggaaggtgagag & \multirow{3}{*}{$\begin{array}{l}283 \text { bp } \\
-210 \text { to }+73 \\
5952-6234\end{array}$} & & \multirow[t]{2}{*}{$55^{\circ} \mathrm{C}$} \\
\hline & & A: ctaacaacaaacatacccaaacaaaac & & NM_000796 & \\
\hline & Second & $\begin{array}{l}\text { S: aaaattaagattaaaaagagtattgaggag } \\
\text { A: ctacttttccaacttccctattaaacc }\end{array}$ & & AC0993010.7 & $53^{\circ} \mathrm{C}$ \\
\hline \multirow[t]{4}{*}{ HTR3A } & First & S: tttttggggaaatatggttaagt & \multirow{4}{*}{$\begin{array}{l}390 \text { bp } \\
-176 \text { to }+214 \\
25226-25615\end{array}$} & & \multirow[t]{2}{*}{$52^{\circ} \mathrm{C}$} \\
\hline & & A: atcaaccaaatcctactacttcc & & NM_000869 & \\
\hline & Second & S: agttttttggttgaatgggtgga & & AP000908.4 & $55^{\circ} \mathrm{C}$ \\
\hline & & A: tctacttaccttctccetatacc & & & \\
\hline
\end{tabular}

${ }^{a}$ Locations relative to cDNA and genomic sequences/genes are indicated in the rows corresponding to the first and second rounds of PCR, respectively

${ }^{\mathrm{b}}$ GenBank accession numbers of cDNA and genomic sequences are described, with NM numbers indicating cDNA and other numbers the genomic sequences of genes

$20 \mu \mathrm{l}$. The PCR products were separated by electrophoresis using a $6.0 \%$ polyacrylamide gel. The intensity of the PCR products was measured using Science Lab
Image Gauge software (Fujifilm, Japan). The primers and PCR conditions used for the RT-PCR assays are shown in Table 3. 
Table 3 Primers and conditions for semi-quantitative RT-PCR. Gene symbols as in Table 1. Ex1a is the authentic first exon of HTR3A and Ex1b may be a novel exon (see Fig. 4 and text)

\begin{tabular}{|c|c|c|c|c|}
\hline Gene & Sense primer $5^{\prime}-3^{\prime}$ & Antisense primer $5^{\prime}-3^{\prime}$ & Annealing temperature & Cycles \\
\hline COMT & agctcagaggagaccccagac & tgggctgcaggatgaactcgt & $58^{\circ} \mathrm{C}$ & $23,26,29$ \\
\hline DRD1 & tgcccccagcgaagtccacat & tcctgggcctctgctctgcta & $62^{\circ} \mathrm{C}$ & $28,31,34$ \\
\hline DRD2 & cgctgcagaccaccaccaact & gtcgatgctgatggcacacaa & $58^{\circ} \mathrm{C}$ & $25,28,31$ \\
\hline NCAM & gcccaggtgcagtttgatgaa & ctgatctcacccagccetttg & $58^{\circ} \mathrm{C}$ & $20,23,26$ \\
\hline HTR2A & tgctgctgggtttccttgtca & tctggagttgaagcggctgtg & $58^{\circ} \mathrm{C}$ & $27,30,33$ \\
\hline HCRT & cggctaccccaccetgag & tcgtagaggcggcaagag & $58^{\circ} \mathrm{C}$ & $28,31,34$ \\
\hline DRD3 & tgcaggagccgaagtggtaaa & atgagcgcgcagtaggagagg & $58^{\circ} \mathrm{C}$ & $28,31,34$ \\
\hline HTR3A & ggtgtgcgeccegtgagg & cegtggggatggacaact & $58^{\circ} \mathrm{C}$ & $28,31,34$ \\
\hline HTR3A (Ex1a) & cttgctcetcccacact & ccgtggggatggacaact & $60^{\circ} \mathrm{C}$ & $30,33,36$ \\
\hline HTR3A (Ex1b) & tgetcttccaagccagat & ccgtggggatggacaact & $58^{\circ} \mathrm{C}$ & $30,33,36$ \\
\hline GAPDH & gaaggtgaaggtcggagtc & gaagatggtgatgggatttc & $60^{\circ} \mathrm{C}$ & $18,21,24$ \\
\hline
\end{tabular}

\section{Results}

Methylation states of genes with or without $\mathrm{CpG}$ islands and of HERV-K loci

We chose four genes, DRD1 (Minowa et al. 1993), DRD2 (Samad et al. 1997), COMT (Tenhunen et al. 1994), and NCAM (Hirsch et al. 1991) that harbor CpG islands in the regulatory or flanking regions of the gene (CpG island genes) and four genes, DRD3 (D'Souza et al. 2001), HTR2A (Zhu et al. 1995), HTR3A (Bedford et al. 1998), and HCRT (Waleh et al. 2001), that do not have $\mathrm{CpG}$ islands in the corresponding regions (non$\mathrm{CpG}$ island genes). All eight genes are predominantly and abundantly expressed in brain. In addition, methylation of the HERV-K family, one of the HERV families classified as human retrotransposons, was examined (Löwer et al. 1996).

We first examined the methylation states of the 5'flanking regions of the genes by Southern blot hybridization using methylation-sensitive restriction enzymes. The $\mathrm{CpG}$ island genes all showed completely cleaved patterns with the exception of COMT in one of the PBL samples (Fig. 1). The partial methylation pattern of COMT in PBL Sample c is most likely the result of incomplete digestion due to insufficient purity of the sample, as well as the enzymatic characteristics of $\mathrm{SacII}$. A similar partial methylation pattern in $D R D 1$ was observed in some PBL samples (data not shown) using SacII, even though the bisulfite method did not detect any methylated $\mathrm{CpG}$ within the $\mathrm{Sac}$ II recognition sequence. We confirmed by bisufite-modified DNA sequencing that all, or almost all, cytosine residues in the $\mathrm{CpG}$ sequences analyzed were unmethylated, as were cytosine residues in non-CpG sequences (Fig. 1).

In contrast, Southern blot hybridization of the non$\mathrm{CpG}$ island genes showed a variety of methylation patterns, depending on the tissue and the gene analyzed (Figs. 2, 3). One of the prominent trends is the methylation status in brain: methylation was very low or absent in all four genes in each of the three individuals. Placental DNA showed the next lowest levels of methylation in the non- $\mathrm{CpG}$ island genes, with the exception of HCRT, while liver DNA revealed a trend towards hypermethylation. PBL also showed hypermethylated patterns of HCRT and HTR3A. DRD3 was unexpectedly extremely hypomethylated in all tissues and individuals examined. Interestingly, differences in the degree of methylation between individuals were observed in $H T R 2 A$ and $H C R T$ in the placental samples: the methylation levels of $H T R 2 A$ and $H C R T$ were lower in Sample a than in Samples b and c (Fig. 2). Although the Southern blot method can reveal the methylation status only of the $\mathrm{CpG}$ sequence within a recognition sequence of a methyl-sensitive restriction enzyme, the results obtained with the bisulfite method were largely consistent with the results of Southern blot hybridization. The inter-individual differences in methylation in $H T R 2 A$ and HCRT were also detected by the bisulfite method.

In addition to the single copy genes, we analyzed the methylation states of a repetitive sequence region of HERV-K by Southern blot hybridization. When the CpG within the SmaI recognition sequence in the $5^{\prime}$ LTR of HERV-K is unmethylated, a Pst I-Sma I fragment of approximately $1.8 \mathrm{~kb}$ is produced from multiple HERV-K loci (Fig. 4, top panel). The blot hybridized with a probe prepared from the gag region yielded numerous signals with various sizes, among which the signal at $1.8 \mathrm{~kb}$ was most intense in the Pst I plus Xma Icleaved lanes, indicated by a black arrowhead in the middle panel in Fig. 4. In contrast, the signal indicated by an open arrowhead at approximately $4.3 \mathrm{~kb}$ in size disappeared in those lanes. Therefore, the $1.8 \mathrm{~kb}$ fragment results in part from the $4.3 \mathrm{~kb}$ fragment. When cutting with Pst I and Sma I, a methyl-sensitive isoschizomer of Xma I, this inverse relation was clearly recognized in the placental samples. We measured the intensities of the 1.8 and $4.3 \mathrm{~kb}$ signals and normalized them relative to an internal control (not shown). Interindividual differences in intensities were observed in both signals in the placental samples, and an inverse relation between the 1.8 and $4.3 \mathrm{~kb}$ signals was evident (Fig. 4, bottom panel). Although the inter-individual 
COMT

(a)

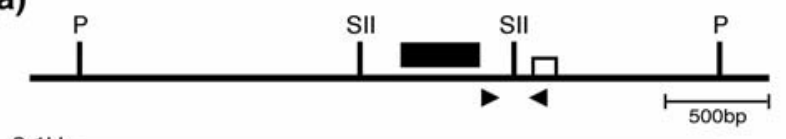

$3.1 \mathrm{~kb}$

$2.1 \mathrm{~kb}$

$1.7 \mathrm{~kb}$

$0.75 \mathrm{~kb}$

(b)

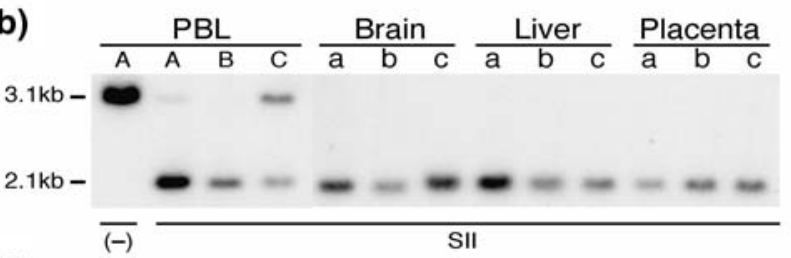

(c)

$\frac{1}{15} \quad 36$

PBL(A) 000000000000000000000000000000000000
Brain(a) 000000000000000000000000000000000000

DRD2

(a)
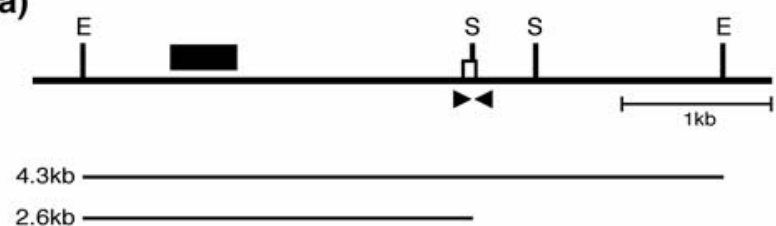

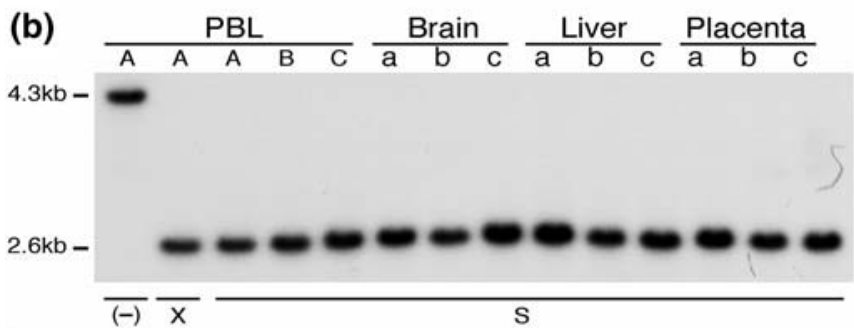

(c)

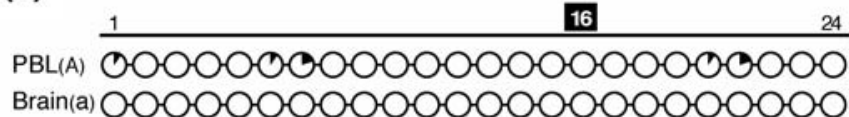

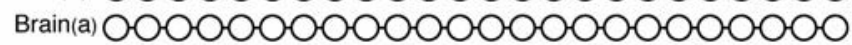

Fig. 1 Methylation analyses of genes with $\mathrm{CpG}$ islands. The three panels $(\mathbf{a}-\mathbf{c})$ presented for each gene show the following. a Schematic of the region analyzed where filled boxes indicate probes for Southern blot analysis, open boxes indicate the first exon of the gene, and arrowheads indicate positions of the primer sets for bisulfite-modified DNA sequencing. Lines under the restriction maps are possible fragments generated by restriction digestion. $\mathbf{b}$ The results of Southern blot analysis. Letters above the lanes indicate samples from different individuals. Samples $a, b$, and $c$ were obtained from fetal tissues and placentas with gestational ages of 16,19 , and 21 weeks, respectively. c Schematic of methylation
DRD1

(a)

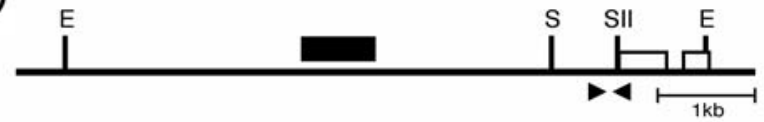

$6.2 \mathrm{~kb}$

$5.3 \mathrm{~kb}$

$4.7 \mathrm{~kb}$

(b)

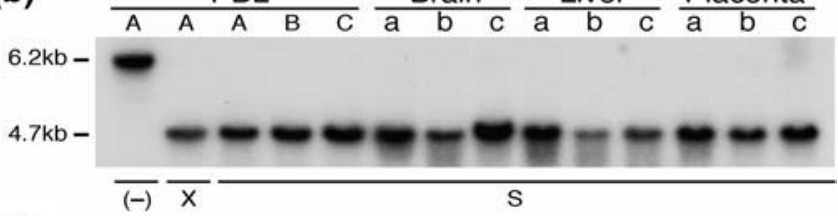

(c)

$\frac{15}{25}$ PBL(A) 000000000000000000000000000000000000 (a)

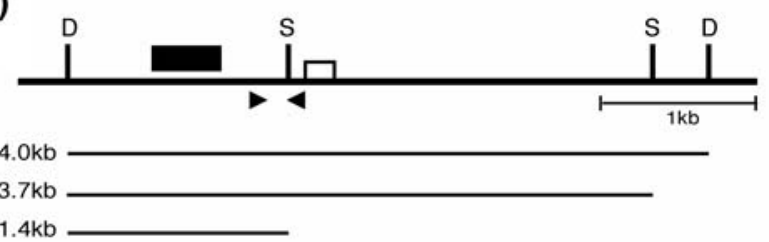

(b)

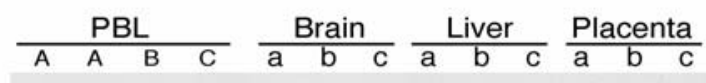

$4.0 \mathrm{~kb}-$

$1.4 \mathrm{~kb}-$

(c) $\overline{(-)}$

13 22 PBL(A) O-00-00-000-00000-000000 Brain(a) 0-0-00-00-0-00-0000-00

states of all cytosines in the $\mathrm{CpG}$ sequence as analyzed by the bisulfite method. Each nucleotide position is represented by a circle summarizing the results of ten clones analyzed. Black sectors indicates the percentage of methylated cytosine. Each number on the line indicates the position of the $\mathrm{CpG}$ region analyzed. The number in the black box indicates the position of the cytosine (in $\mathrm{CpG}$ ) in the recognition sequences for methyl-sensitive restriction enzymes. P PstI, S II SacII, E EcoRI, S SmaI, D DraI, COMT catechol-O-methyltransferase, DRD1 dopamine receptor D1, $D R D 2$ dopamine receptor D2, NCAM neural cell adhesion molecule, $P B L$ peripheral blood leukocytes 
HTR2A

(a)

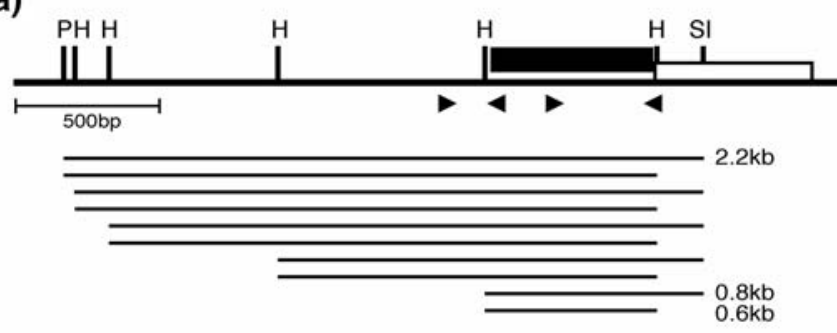

(b)
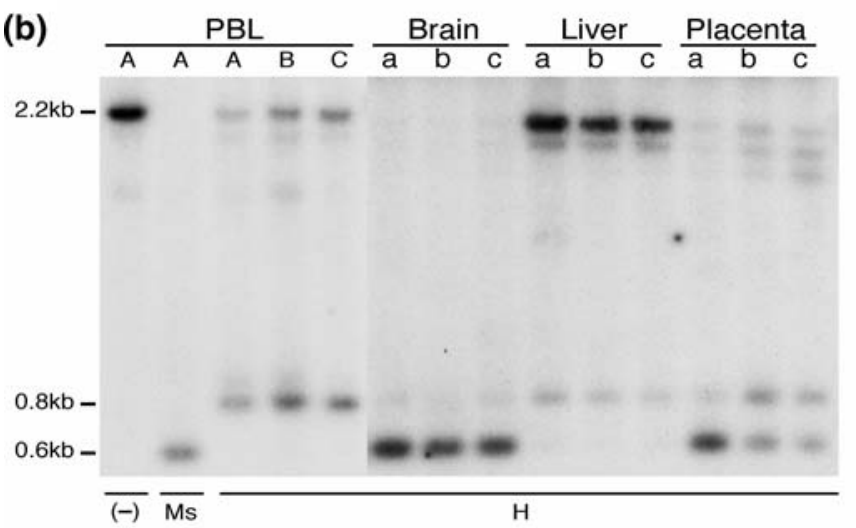

(c)

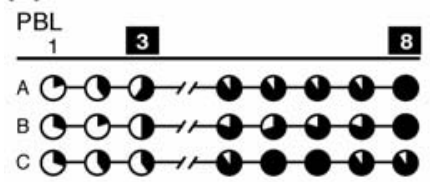

8

Brain

a $\mathrm{O}-\mathrm{O}-\mathrm{O}-1-\mathrm{O}-\mathrm{O}-\mathrm{O}-\mathrm{O}-\mathrm{O}$

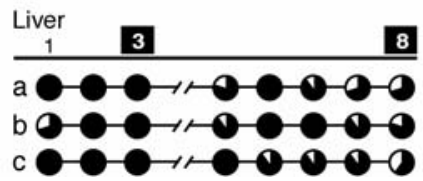

8

$c 0-0-0-1-0-0-0-0-0$

Placenta 3

8

a O-O-O- $-0-0-0-0-0$

b $0-0-0-1-0-0-0$

$c$ o- - - $1-0-0-0-0$ (a)
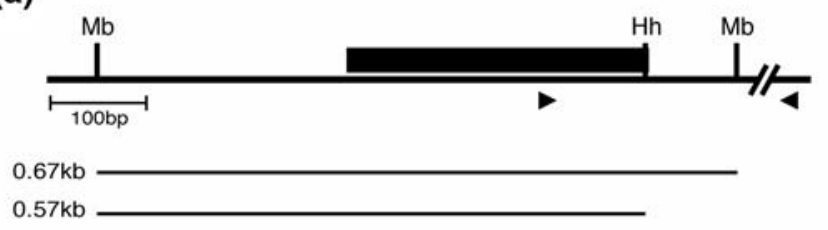

(b)
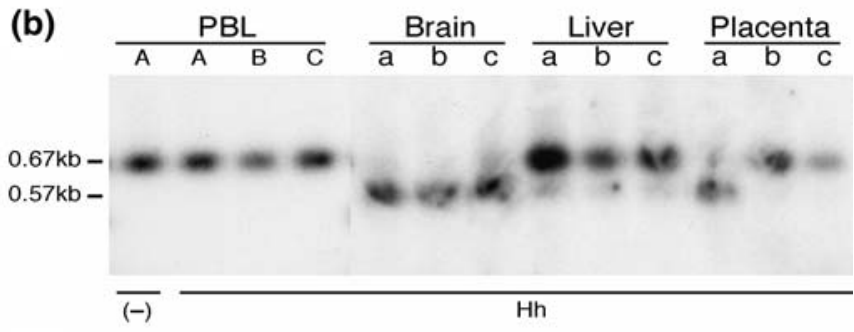

(c)

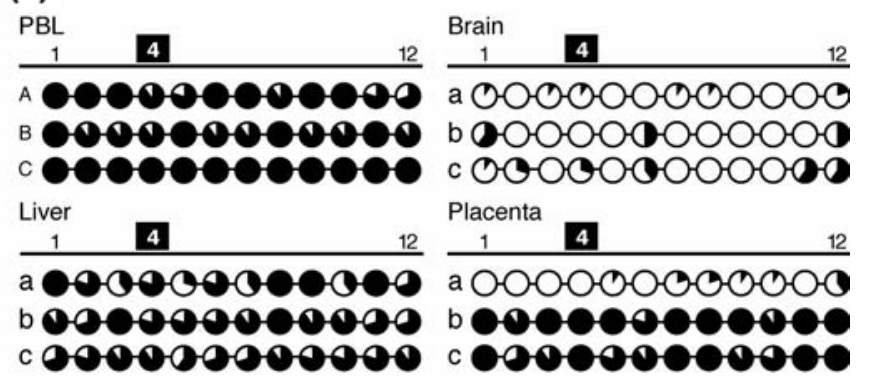

Fig. 2 Methylation analyses of genes without $\mathrm{CpG}$ islands. Description of panels a-c for each gene and symbols as in Fig. 1. P Pst I, H HpaII, S I SacI, Mb MboI, Hh HhaI, HTR2A 5-hydroxytryptamine receptor 2A, HCRT hypocretin (also called orexin)

differences in intensity were not detected in the $1.8 \mathrm{~kb}$ signal in the liver samples, possibly due to overall weak signal intensity, differences could be clearly seen in the $4.3 \mathrm{~kb}$ signal intensity, and the trend was similar to that in the placental samples. Sample a was most strongly methylated and Sample c most hypomethylated in both the placenta and liver.

Expression analysis by semi-quantitative RT-PCR

To examine the relationship between DNA methylation and gene expression, we estimated steady state levels of mRNA transcribed from each of the eight genes by semiquantitative RT-PCR. The amount of RT product used as a template for PCR was adjusted relative to the internal control glyceraldehydes-3-phosphate dehydrogenase $(G A P D H)$. Primer pairs were located in exons of the corresponding genes.
Among the four genes with $\mathrm{CpG}$ islands, all but $C O M T$ were exclusively or predominantly expressed in the brain (Fig. 5). COMT was actively expressed in all of the tissues examined, consistent with the results of Tenhunen et al. (1994). The PCR products of DRDI and $D R D 2$ were detected in placental samples three to six cycles later than in brain samples. The NCAM PCR product was barely detected in the other tissues after the maximum number of cycles. Thus, the transcriptional activity of the three $\mathrm{CpG}$ island genes, $D R D 1, D R D 2$, and $N C A M$, was much lower in the liver, placenta, and in PBL than in the brain, and these same genes showed little or no methylation in their promoter regions.

The non- $\mathrm{CpG}$ island genes were also expressed most abundantly in the brain among the four tissues examined (Fig. 5). HTR2A was expressed in the other three tissues, albeit at very low levels. $H C R T$ and $D R D 3$ showed low levels of expression in the placenta and PBL, respectively. Unlike these genes, $H T R 3 A$ was expressed 
HTR3A

(a)

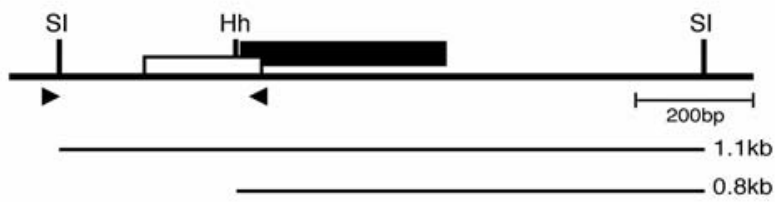

(b)

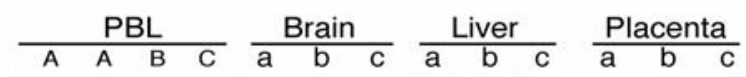

$1.1 \mathrm{~kb}-\mathrm{em} \mathrm{em}$

$0.8 \mathrm{~kb}-$

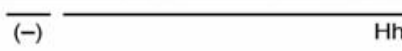

(c)

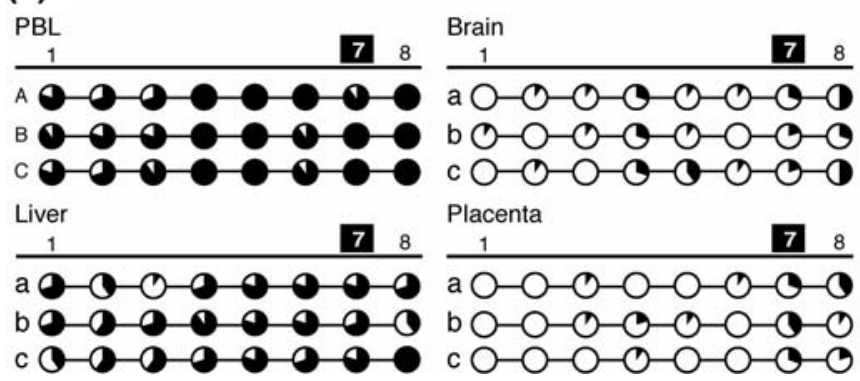

Fig. 3 Methylation analyses of genes without $\mathrm{CpG}$ islands. Open boxes indicate the first exons of the genes; the first exon of HTR $3 \mathrm{~A}$ corresponds to Exla described in Fig. 6. Description of panels a-c

in the liver and PBL at levels similar to that found in brain, even though the gene was heavily methylated in both tissues. The discrepancy between the expression and methylation of $H T R 3 A$ prompted a database search in which we found an EST (GenBank accession number, BG341613) from primary B cells from tonsils that was located between the first and second exons of HTR $3 \mathrm{~A}$ (Ex1b in Fig. 6). Using new primers designed from Ex $1 \mathrm{~b}$ and a downstream exon produced a PCR product of the expected size in the liver and PBL, but no product was detected in the brain. In contrast, another primer from Exla yielded a PCR product detected in the brain, and in the liver at very low levels (Fig. 6). These data suggest that HTR3A may have at least two promoters: an upstream promoter used in the brain and a downstream one used in PBL and liver.

\section{Discussion}

In spite of the general recognition that DNA methylation plays an important role in biological functions, studies implicating methylation in the pathogenesis of inherited diseases, especially psychiatric disorders, are still very limited. Here, we investigated methylation states in or near the promoter regions of eight single
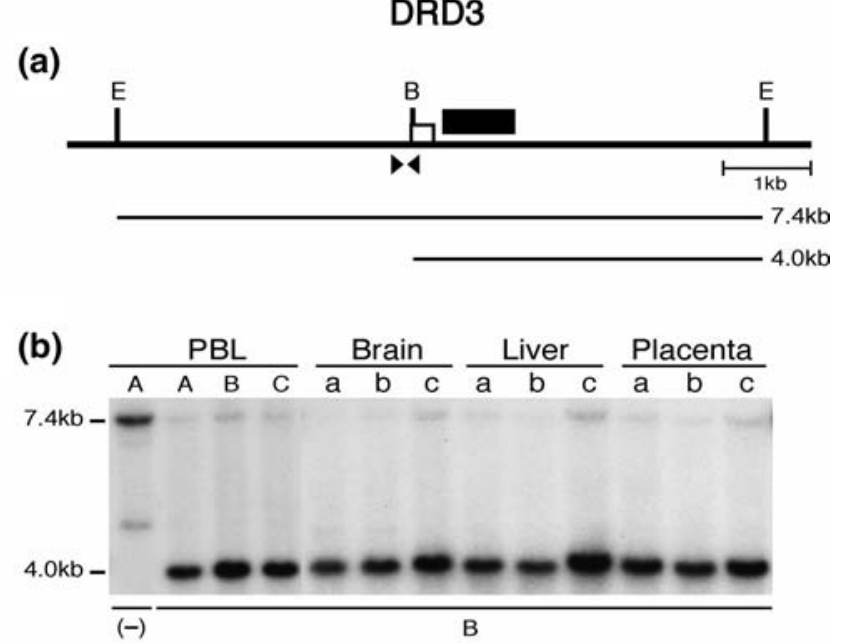

(c)

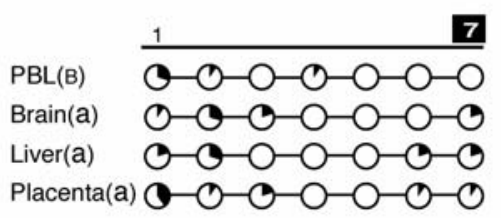

for each gene and symbols as in Fig. 1. B Methyl-sensitive restriction enzyme Bst $\mathrm{BI}, H T R 3 A$ 5-hydroxytryptamine receptor $3 \mathrm{~A}, D R D 3$ dopamine receptor D3

copy genes and one type of repetitive sequence, HERV$\mathrm{K}$, by the bisufite and/or Southern blot method(s).

The results obtained by the two methods were largely consistent. Each method has some inherent limitations, for example, artifactual partial digestion in the Southern blot method (Fig. 1, COMT in the PBL Sample c) and biased amplification and cloning in the bisulfite method. The Southern blot method was useful to identify the presence of biases and had the additional advantage of providing a visual representation of methylation states spanning several kilobases. Nevertheless, both methods are time-consuming and laborious, limiting the extent of the analysis. Genome-wide analyses of DNA methylation need more robust methods, such as that demonstrated in a recent study (Weber et al. 2005).

Half of the eight single copy genes had $\mathrm{CpG}$ islands in the $5^{\prime}$ flanking regions ( $\mathrm{CpG}$ island genes), and these $\mathrm{CpG}$ sequences were unmethylated in the four tissues examined. Among the four $\mathrm{CpG}$ island genes, all but COMT were predominantly expressed in the brain. COMT was abundantly expressed in all four tissues examined. Thus, the cytosines in the $\mathrm{CpG}$ islands were protected from methylation, regardless of the transcriptional state of the gene, which is consistent with the general recognition of hypomethylation in $\mathrm{CpG}$ islands 

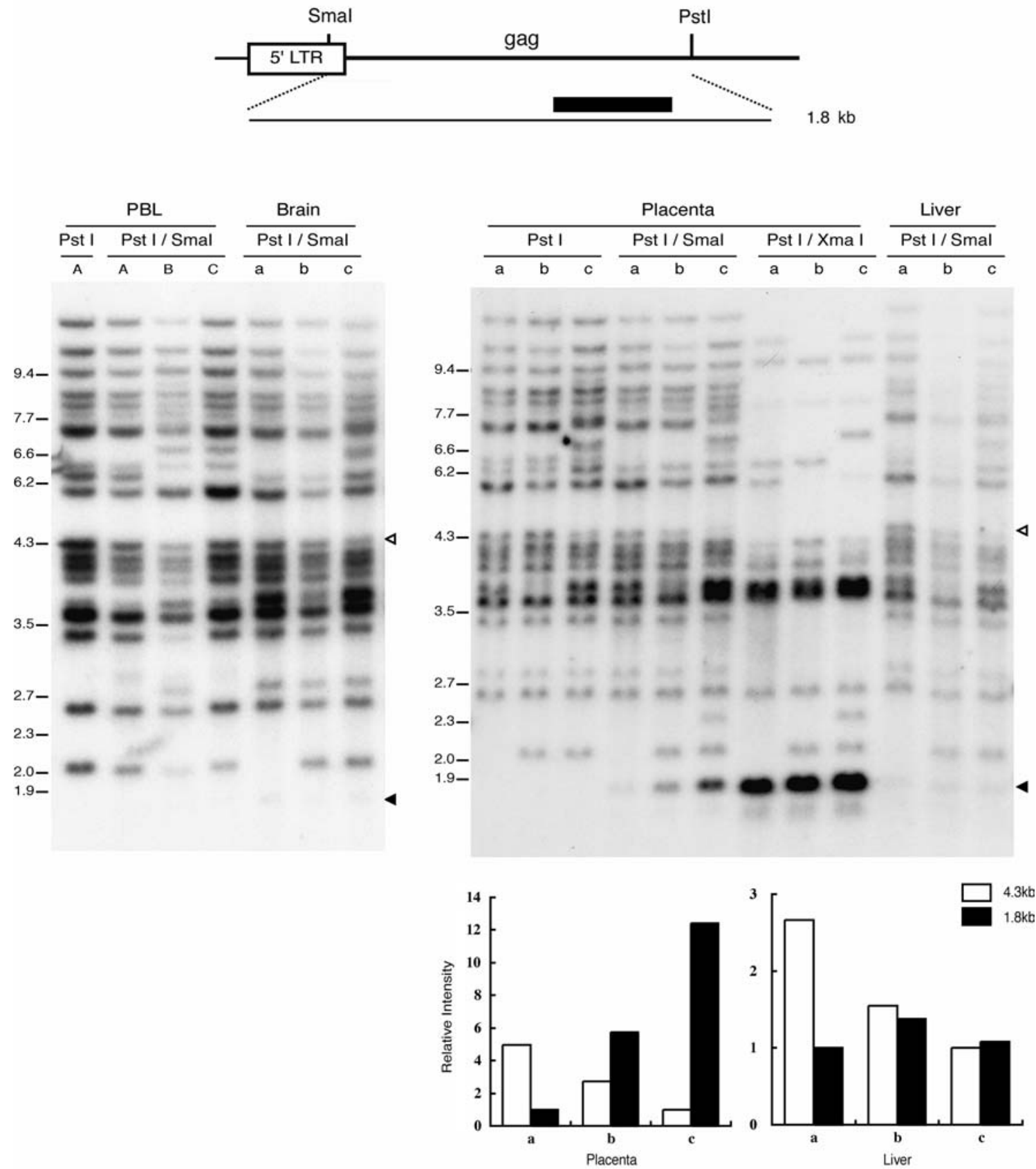

Fig. 4 Methylation analysis of human endogenous retrovirus (HERV)-K. Part of a typical HERV-K (5' LTR and gag region) is shown at the top. The flanking sequence is depicted by a thin line. A black bar indicates the location of the probe used for Southern blot hybridization. The middle panels show the Southern hybridization results. Letters above the lanes indicate samples from

different individuals. Two bands that showed inter-individual differences in signal intensity are indicated by open and filled triangles. The intensities of these two signals were quantified by the Science Lab Image Gauge software (Fujifilm, Japan) and normalized relative to an internal control (not shown). The bottom panel shows the normalized intensities for each band

except for either allele of the $\mathrm{X}$ chromosome genes in females and imprinted genes (Yoder et al. 1997).

The non-CpG island genes revealed a variety of methylation patterns that were different between tissues, genes, and even between individuals (Fig. 2, placental Samples a versus $\mathrm{b}$ and $\mathrm{c}$ in $H T R 2 A$ and $H C R T$ ). The only common feature was hypomethylation in the brain samples in all four non-CpG island genes. In general, methylation in regulatory regions of a gene suppresses the transcriptional activity of that gene. However, HTR $3 A$ was heavily methylated in the liver and PBL samples, and was actively transcribed in these tissues. We subsequently identified an EST whose sequence was located between the first and second exons of HTR $3 \mathrm{~A}$. RT-PCR with a primer located in the authentic exon 1 (Ex1a in Fig. 6) and a common primer amplified a 
COMT
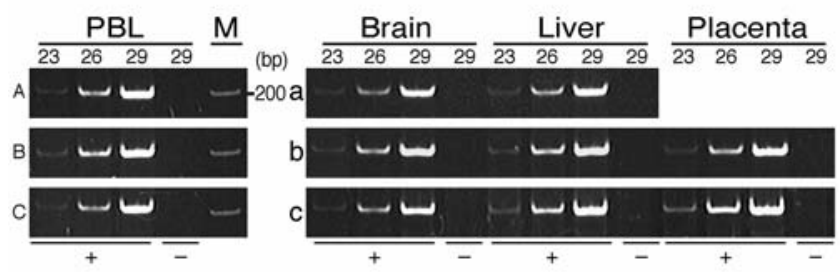

DRD2

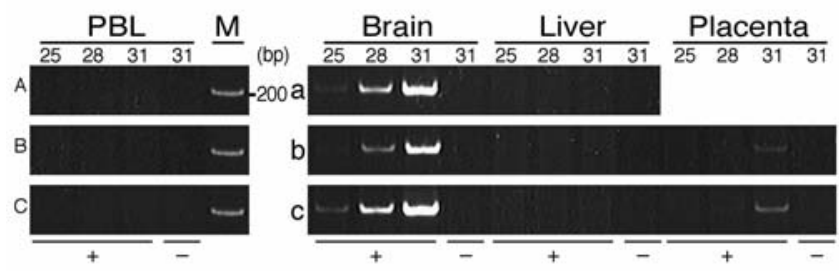

HTR2A
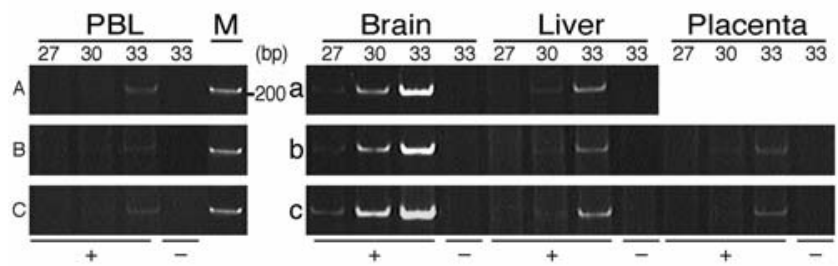

HTR3A
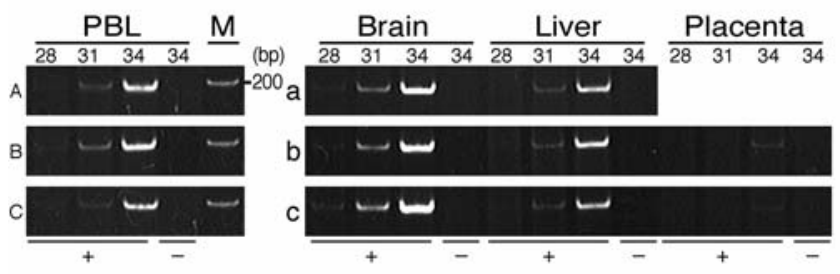

\section{GAPDH}

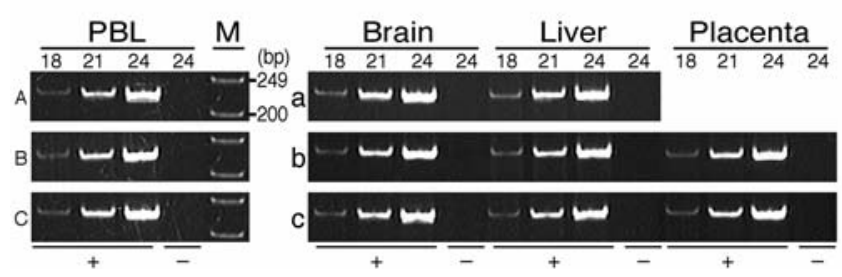

Fig. 5 Semi-quantitative analysis of the expression of the eight single copy genes. The amount of cDNA (reverse transcription products) used for PCR was adjusted relative to that of an internal control gene, glyceraldehydes-3-phosphate dehydrogenase (GAP-

product from brain cDNA, but much less abundantly from liver samples, and nothing was detected after the maximum number of cycles in the PBL and placenta samples. In contrast, RT-PCR with a novel exon-specific primer (Ex1b in Fig. 6) and the common primer did not produce a PCR product from brain, while amplification was clearly observed in the liver and PBL samples. Thus, HTR3A may be transcribed from a brain-specific

\section{DRD1}

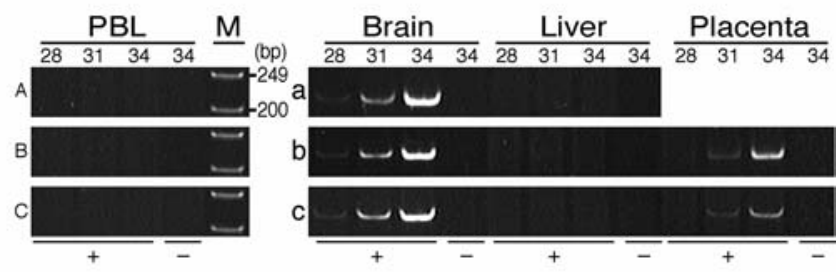

\section{NCAM}

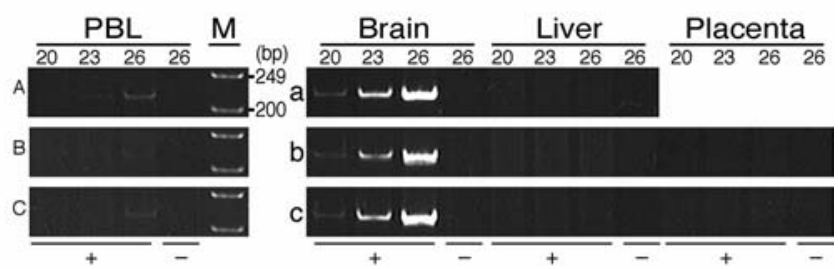

HCRT

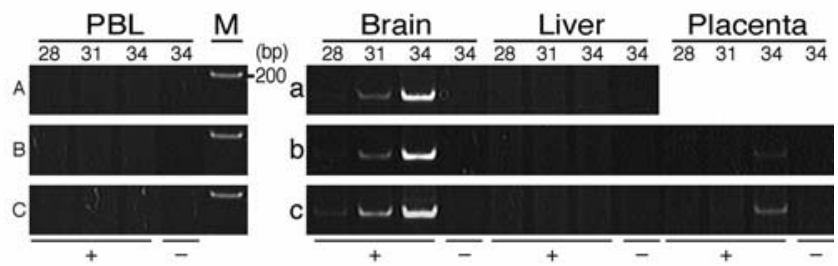

DRD3

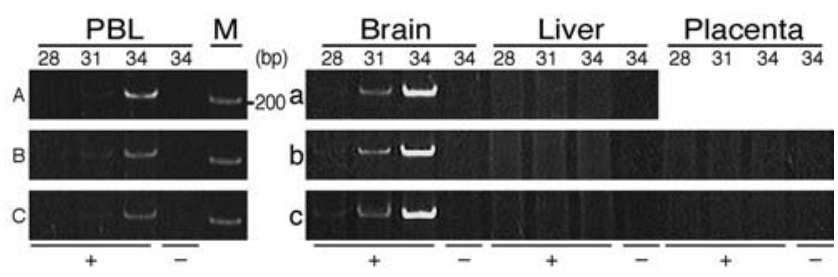

$D H$ ). Equal volumes of PCR reaction mixes at the cycles indicated by the numbers above the lanes were fractionated in $4 \%$ polyacrylamide gels and stained with ethidium bromide. RNA from placental Sample a was not available. Gene symbols as in Fig. 1

promoter in the brain and from a different promoter in PBL and liver. HTR $2 A$ may also possess tissue-specific promoters, although $H T R 2 A$ expression in the liver and PBL was much lower than in brain. Bunzel et al. (1998) reported polymorphic imprinting in expression of $H T R 2 A$ in the human adult brain. The methylation pattern in the PBL, albeit not in the brain, seemed consistent with a differentially methylated region as 
HTR3A

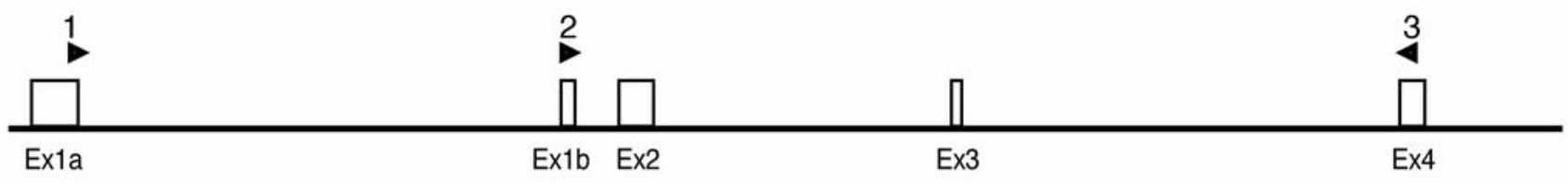

Primer 1-3
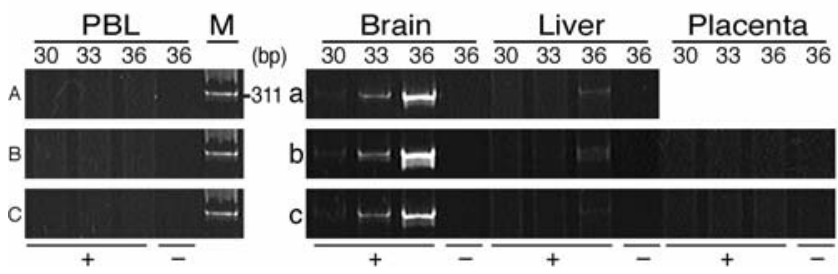

Fig. 6 HTR3A transcription from a brain-specific promoter and a novel putative promoter. Upper panel HTR $3 A$ gene structure. The boxes on the line indicate the relative size and location of the exons. The transcript-specific primers 1 and 2, and the common primer 3 are shown schematically. Exla is the first exon of HTR $3 A$ and Ex1b is the alternative exon 1 that is possibly transcribed from

found in imprinted genes (Robertson 2005). The methylation states in DRD3 were also inconsistent with the expression status. Despite lacking the $\mathrm{CpG}$ island, $D R D 3$ was not methylated in the liver and placenta, where the DRD3 transcript was not detected. Thus, our data suggest that for non-CpG island genes 5 '-flanking regions are not methylated in any tissues in which the genes are actively expressed, but the converse is not necessarily true.

We are interested in the presence of methylation differences between individuals. In this study, we found inter-individual differences in methylation in two genes, $H T R 2 A$ and $H C R T$, in the placental samples. Sample a showed much lower methylation in both these genes than in Samples b and c. We were unable to determine the methylation-expression relationship of $H T R 2 A$ and $H C R T$ because RNA was not available from Sample a.

To examine multiple loci and the relationship between methylation in single copy genes and repetitive sequences, we examined the HERV-K methylation status and identified two signals that showed inter-individual differences in signal intensity in placental and liver samples. The two signals possibly consist of multiple loci, with the larger one having a Sma I recognition sequence (CCCGGG) and the smaller one resulting from Sma I digestion of this locus. The inter-individual differences were most distinctive in the placental samples, with methylation highest in Sample a, moderate in Sample b, and lowest in Sample c, which is the reverse of the trend seen in HTR2A and HCRT. In addition, this order was the same as found in the liver samples. The reasons for inter-individual methylation differences remain to be ascertained, but here we could exclude a developmental effect on DNA methylation because we found opposite trends in different genes and our previous study revealed
Primer 2-3

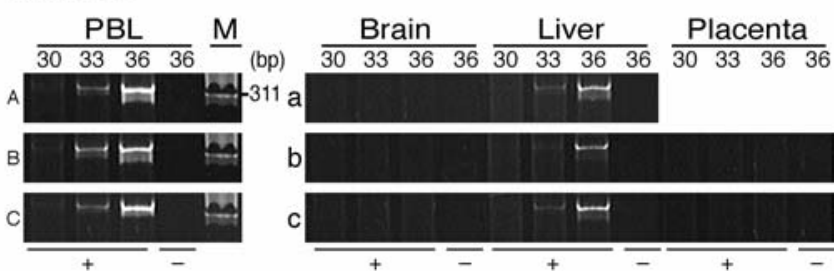

another promoter. Lower panel Tissue specificity of the transcripts generated with Primers 1 and 3 or from Primers 2 and 3. Numbers above the lanes indicate the number of amplification cycles and + or - below the lanes indicates whether reverse transcriptase was included in the reverse transcription reaction followed by the PCR reaction. Letters indicate samples from different individuals that methylation levels undergo global changes in the developing placenta (Fuke et al. 2004).

To date, the most widely used methods for DNA methylation analysis are Southern blot hybridization in combination with methyl-sensitive restriction enzymes and bisulfite-modified DNA sequencing. Both methods have intrinsic weaknesses, an artifactual partial methylation in the former and biased amplification and cloning in the latter. In our present study on DNA methylation, these methods were complementary and provided very reliable basic data on methylation status within or near the promoter region of genes whose activities are essential to development and brain function. We additionally determined the relationship between methylation and expression of these genes. Furthermore, we identified inter-individual differences in DNA methylation, which may be helpful in elucidating methylation mechanisms. It is especially worth noting that the difference in HERV-K methylation levels between individuals clearly observed in the placenta was also detected in the liver. This finding may support our approach and hypothesis to explore the possible implications of epigenetics in the molecular etiology of psychiatric disorders (Nakamura et al. 2003; Fuke et al. 2004, and unpublished data). Recently, a genome-wide methylation analysis was performed using a novel combination of existing methods (Weber et al. 2005), and this approach will contribute to rapid progress in understanding the etiological roles of DNA methylation in the pathogenesis of common diseases, especially psychiatric disorders.

Acknowledgments We thank Drs. K. Higashimoto, H. Soejima, K. Miura, and T. Miyamoto for their help. Prof. Y. Okazaki was supported by a Grant-in-Aid for Scientific Research (A) (No. 13307027). 


\section{References}

Abdolmaleky HM, Thiagalingam S, Wilcox M (2005) Genetics and epigenetics in major psychiatric disorders: dilemmas, achievements, applications, and future scope. Am J Pharmacogenomics $5: 149-160$

Ahuja N, Issa JP (2000) Aging, methylation and cancer. Histol Histopathol 15:835-842

Bedford FK, Julius D, Ingraham HA (1998) Neuronal expression of the 5HT3 serotonin receptor gene requires nuclear factor 1 complexes. J Neurosci 18:6186-6194

Bickmore WA, van der Maarel SM (2003) Perturbations of chromatin structure in human genetic disease: recent advances. Hum Mol Genet 12:R207-R213

Bunzel R, Blumcke I, Cichon S, Normann S, Schramm J, Propping P, Nothen MM (1998) Polymorphic imprinting of the serotonin-2A (5-HT2A) receptor gene in human adult brain. Brain Res Mol Brain Res 59:90-92

D'Souza UM, Wang W, Gao DQ, Kanda S, Lee G, Junn E, Hwang CK, Jose PA, Mouradian MM (2001) Characterization of the $5^{\prime}$ flanking region of the rat $\mathrm{D}(3)$ dopamine receptor gene. J Neurochem 76:1736-1744

Fuke C, Shimabukuro M, Petronis A, Sugimoto J, Oda T, Miura K, Miyazaki T, Ogura C, Okazaki Y, Jinno Y (2004) Age related changes in 5-methylcytosine content in human peripheral leukocytes and placentas: an HPLC-based study. Ann Hum Genet 68:196-204

Grunau C, Clark SJ, Rosenthal A (2001) Bisulfite genomic sequencing: systematic investigation of critical experimental parameters. Nucleic Acids Res 29:E65

Hirsch MR, Valarche I, Deagostini-Bazin H, Pernelle C, Joliot A, Goridis C (1991) An upstream regulatory element of the NCAM promoter contains a binding site for homeodomains. FEBS Lett 287:197-202

Hsieh CL (2000) Dynamics of DNA methylation pattern. Curr Opin Genet Dev 10:224-228

Jaenisch R, Bird A (2003) Epigenetic regulation of gene expression: how the genome integrates intrinsic and environmental signals. Nat Genet 33:245-254

Jones PA, Laird PW (1999) Cancer epigenetics comes of age. Nat Genet 21:163-167

Löwer R, Löwer J, Kurth R (1996) The viruses in all of us: characteristics and biological significance of human endogenous retrovirus sequences. Proc Natl Acad Sci USA 93:5177-5184

Minowa MT, Minowa T, Mouradian MM (1993) Activator region analysis of the human D1A dopamine receptor gene. J Biol Chem 268:23544-23551

Morgan HD, Sutherland HG, Martin DI, Whitelaw E (1999) Epigenetic inheritance at the agouti locus in the mouse. Nat Genet 23:314-318
Nakamura A, Okazaki Y, Sugimoto J, Oda T, Jinno Y (2003) Human endogenous retroviruses with transcriptional potential in the brain. J Hum Genet 48:575-581

Rakyan VK, Blewitt ME, Druker R, Preis JI, Whitelaw E (2002) Metastable epialleles in mammals. Trends Genet 18:348-351

Razin A (1998) CpG methylation, chromatin structure and gene silencing-a three-way connection. EMBO J 17:4905-4908

Robertson KD (2005) DNA methylation and human disease. Nat Rev Genet 6:597-610

Robertson KD, Wolffe AP (2000) DNA methylation in health and disease. Nat Rev Genet 1:11-19

Roemer I, Reik W, Dean W, Klose J (1997) Epigenetic inheritance in the mouse. Curr Biol 7:277-280

Samad TA, Krezel W, Chambon P, Borrelli E (1997) Regulation of dopaminergic pathways by retinoids: activation of the D2 receptor promoter by members of the retinoic acid receptorretinoid X receptor family. Proc Natl Acad Sci USA 94:1434914354

Sambrook J, Fritsch EF, Maniatis T (1989) Molecular cloning: a laboratory manual, 2nd edn. Cold Spring Harbor Laboratory Press, Cold Spring Harbor, NY

Shahbazian MD, Zoghbi HY (2002) Rett syndrome and MeCP2 linking epigenetics and neuronal function. Am J Hum Genet $71: 1259-1272$

Singal R, Grimes SR (2001) Microsoft Word macro for analysis of cytosine methylation by the bisulfite deamination reaction. Biotechniques 30:116-120

Sutherland HG, Kearns M, Morgan HD, Headley AP, Morris C, Martin DI, Whitelaw E (2000) Reactivation of heritably silenced gene expression in mice. Mamm Genome 11:347-355

Tenhunen J, Salminen M, Lundstrom K, Kiviluoto T, Savolainen R, Ulmanen I (1994) Genomic organization of the human catechol O-methyltransferase gene and its expression from two distinct promoters. Eur J Biochem 223:1049-1059

Thomassin H, Flavin M, Espinas ML, Grange T (2001) Glucocorticoid-induced DNA demethylation and gene memory during development. EMBO J 20:1974-1983

Waleh NS, Apte-Deshpande A, Terao A, Ding J, Kilduff TS (2001) Modulation of the promoter region of prepro-hypocretin by alpha-interferon. Gene 262:123-128

Weber M, Davies JJ, Wittig D, Oakeley EJ, Haase M, Lam WL, Schubeler D (2005) Chromosome-wide and promoter-specific analyses identify sites of differential DNA methylation in normal and transformed human cells. Nat Genet 37:853-862

Wolff GL, Kodell RL, Moore SR, Cooney CA (1998) Maternal epigenetics and methyl supplements affect agouti gene expression in Avy/a mice. Faseb J 12:949-957

Yoder JA, Walsh CP, Bestor TH (1997) Cytosine methylation and the ecology of intragenomic parasites. Trends Genet 13:335-340

Zhu QS, Chen K, Shih JC (1995) Characterization of the human 5HT2A receptor gene promoter. J Neurosci 15:4885-4895 